University of Nebraska - Lincoln

DigitalCommons@University of Nebraska - Lincoln

1995

\title{
A simple technique to measure stress in ultrathin films during growth
}

D. Sander

Max-Plan\&-Institut fur Mikrostrukturphysik, Weinberg 2, 06120-Halle, Germany

Axel Enders

University of Nebraska at Lincoln, a.enders@me.com

J. Kirschner

Max-Plan\&-Institut fur Mikrostrukturphysik, Weinberg 2, 06120-Halle, Germany

Follow this and additional works at: https://digitalcommons.unl.edu/physicsenders

Part of the Physics Commons

Sander, D.; Enders, Axel; and Kirschner, J., "A simple technique to measure stress in ultrathin films during growth" (1995). Axel Enders Publications. 19.

https://digitalcommons.unl.edu/physicsenders/19

This Article is brought to you for free and open access by the Research Papers in Physics and Astronomy at DigitalCommons@University of Nebraska - Lincoln. It has been accepted for inclusion in Axel Enders Publications by an authorized administrator of DigitalCommons@University of Nebraska - Lincoln. 


\title{
A simple technique to measure stress in ultrathin films during growth
}

\author{
D. Sander, A. Enders, and J. Kirschner \\ Max-Planck-Institut für Mikrostrukturphysik, Weinberg 2, 06I20-Halle, Germany
}

(Received 17 April 1995; accepted for publication 17 May 1995)

\begin{abstract}
We demonstrate an easy implementation of the cantilever bending beam approach to measure stress during film growth in ultrahigh vacuum. Using a simple and compact optical deflection technique, film stress with sub-monolayer sensitivity can be detected. A stress measurement during $\mathrm{FeSi}_{2}$ formation on $\mathrm{Si}(111)$ is presented. (C) 1995 American Institute of Physics.
\end{abstract}

The goal of this note is to show how film stress can be measured during growth with sub-monolayer sensitivity at basically any window of an ultrahigh vacuum (UHV) chamber. Just an unobstructed sight of the sample during growth must be possible through this window. Thus, the often somewhat elaborate and specialized experiments described previously $^{1-4}$ are not necessarily the only ways to measure stress. Especially, the long optical path of 1-3 m, with its inherent vibrational problems, employed by others ${ }^{1,2}$ is not required in our setup. Of course, the simplicity of our approach does not give the outstanding sensitivity nor the thermal stability of the designs mentioned above. But in such cases where thin $(\approx 0.1 \mathrm{~mm})$ substrates are readily available (e.g., glass, mica, Si) and the expected stress values are of the order of $1 \mathrm{~N} / \mathrm{m}$ per monolayer deposition, stress measurements can be performed quite easily. The only tribute that has to be paid to the stress measurement in terms of in vacuo modifications is the use of a sample holder, that clamps only one end of the sample. The other end has to be free, as to allow for a free bending of the sample. Figure 1 shows a

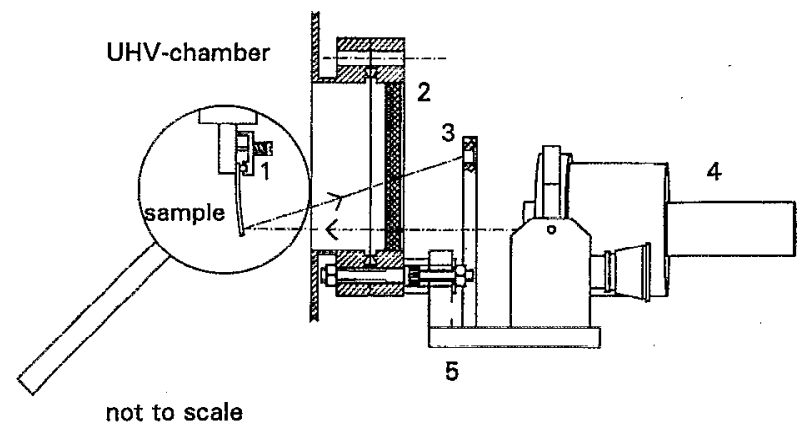

FIG. 1. Schematic of the optical deflection setup. The laser and split photodiode are mounted on one platform attached to a UIIV flange. The laser beam is reflected from the sample to the photodiode. Note that the sample is clamped only at the top end to allow for a free bending. The distance sample photodiode is $240 \mathrm{~mm}$. 1: sample holder; 2: UHV window flange; 3: splitphotodiode; 4: HeNe laser; 5: platform with gimbal mount for convenient alignment of the laser. schematic of our setup. The basic idea of all stress measurements is that a sample will curve a little bit when exposed to film stress on one of its surfaces. We use an $e$-beam evaporator as an $\mathrm{Fe}$ source. This Fe evaporator is aligned in such a way that an $\mathrm{Fe}$ beam of $\sim 8 \mathrm{~mm}$ diam. hits the frontside of the sample. There is no direct path for Fe atoms to reach the backside of the sample, thus any deposition of $\mathrm{Fe}$ on the backside can be excluded. Using an optical deflection technique, we monitor the curvature of the sample during the deposition of $\mathrm{Fe}$ from the atmospheric side of a UHV window. The film stress $\sigma_{F}$ is then calculated from the sample curvature $R$ by applying Stoney's formula: $:^{5,6}$

$$
\sigma_{F}=\frac{E t_{s}^{2}}{6 R(1-\nu) t_{F}}
$$

In the case of ultrathin films, the ratio of sample thickness $t_{s}$ to film thickness $t_{F}, t_{s} / t_{F}$ is of the order $10^{4}$, thus only

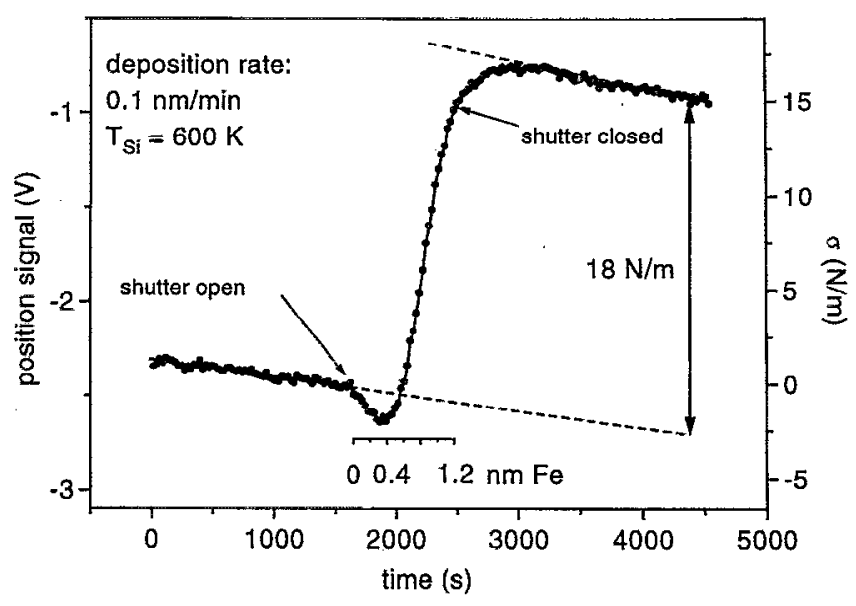

FIG. 2. Stress measurements taken during Fe deposition on $\mathrm{Si}(111)$ at $T_{\mathrm{St}}=600 \mathrm{~K}$. A compressive stress is measured for the first $0.3 \mathrm{~nm}$ of $\mathrm{Fe}$ deposition. The tensile stress of $18 \mathrm{~N} / \mathrm{m}$ for $1.2 \mathrm{~nm}$ of $\mathrm{Fe}$ deposited is measured as the offset between the thermal drift lines. 
Young's modulus $E$ and Poisson's ratio $\nu$ of the sample enter the formula via $E /(1-\nu)$. In the ultrathin limit, the film thickness is hard to define, then the stress is given as $\sigma=\sigma t_{F}$, in units of $\mathrm{N} / \mathrm{m}$. Values for $E /(1-\nu)$ are calculated from the elastic constants of the substrate, e.g., $E /(1-\nu)=2.29 \times 10^{11}$ $\mathrm{N} / \mathrm{m}^{2}$ for $\mathrm{Si}(111){ }^{7}$ For a film stress of $1 \mathrm{~N} / \mathrm{m}$, typical for a $0.1 \mathrm{~nm}$ thick film, a sample curvature for $t_{S}=0.15 \mathrm{~mm}$ of $R=860 \mathrm{~m}$ is expected. For a sample length of $12 \mathrm{~mm}$, this leads to a sample deflection of $84 \mathrm{~nm}$ at the bottom end. Using the bottom end as a mirror, this deflection causes a displacement of the reflected laser beam at the split photodiode of $10 \mu \mathrm{m}$. This displacement is easily measured using a difference and sum amplifier ${ }^{8}$ for processing the signals from the split diode. To keep vibrational noise low, it is essential to mount laser and detector on a common platform, directly attached to a window flange. Thus, relative movements between laser and detector are easily minimized, which otherwise would severely interfere with the stressinduced signal.
In Fig. 2, we present a stress measurement during the growth of $1.2 \mathrm{~nm} \mathrm{Fe}$ on a $\mathrm{Si}(111)$ substrate at $T_{\mathrm{Si}}=600 \mathrm{~K}$. From this measurement, it is obvious that a sub-monolayer sensitivity can be obtained for this extremely simple setup. Note how the stress, induced by depositing as little as $0.1 \mathrm{~nm}$ of $\mathrm{Fe}$, is easily detected to be $0.5 \mathrm{~N} / \mathrm{m}$. Further deposition of $\mathrm{Fe}$ leads to the formation of $\beta-\mathrm{FeSi}_{2}$. This silicide formation induces a huge tensile stress of $18 \mathrm{~N} / \mathrm{m}$. A detailed discussion of the stress during growth of $\mathrm{Fe}$ on $\mathrm{Si}$ can be found elsewhere.

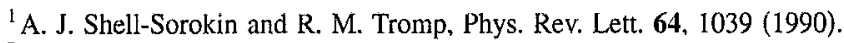

${ }^{2}$ R. E. Martinez, W. A. Augustyniak, and J. A. Golovchenko, Phys. Rev. Lett. 64, 1035 (1990).

${ }^{3}$ D. Sander and H. Ibach, Phys. Rev. B 43, 4263 (1991).

${ }^{4}$ M. Weber, R. Koch, and K. H. Rieder, Phys. Rev. Lett. 73, 1166 (1994).

${ }^{5}$ G. G. Stoney, Proc. R. Soc. London Ser. A 82, 172 (1909).

${ }^{6}$ A. Brenner and S. Senderoff, J. Res. Natl. Bur. Stand. 42, 105 (1949).

${ }^{7}$ W. A. Brantley, J. Appl. Phys. 44, 534 (1972).

${ }^{8}$ United Detector Technology: Amplifier Model 307 DIV, through LASER 2000, Argelsrieder Feld 14, 82234 Wessling, Germany.

${ }^{9}$ D. Sander, A. Enders, and J. Kirschner, Appl. Phys. Lett. (submitted). 